\title{
Intra-specific variation in lichen secondary compounds across environmental gradients on Signy Island, maritime Antarctic
}

\author{
Stef Bokhorst $^{1}$ (D) Johan Asplund ${ }^{2}$ D $\cdot$ Peter Convey $^{3}$ (D)
}

Received: 26 October 2020 / Revised: 10 February 2021 / Accepted: 2 March 2021

(c) The Author(s) 2021

\begin{abstract}
Lichens produce various carbon-based secondary compounds (CBSCs) in response to abiotic conditions and herbivory. Although lichen CBSCs have received considerable attention with regard to responses to UV-B exposure, very little is known about intra-specific variation across environmental gradients and their role in protection against herbivory in the Antarctic. Here we report on the variation in CBSCs of two widely distributed and common Antarctic lichens, Usnea antarctica and Umbilicaria antarctica, between sites with different solar exposure (NW-SE) and along natural nitrogen (N) gradients which are associated with changing lichen-invertebrate associations on Signy Island (South Orkney Islands, maritime Antarctic). Fumarprotocetraric and usnic acid concentrations in Usnea showed no relationships with solar exposure, lichen-N or associated invertebrate abundance. However, fumarprotocetraric acid concentration was 13 times higher at inland sites compared to coastal sites along the N-gradients. Gyrophoric acid concentration in Umbilicaria was 33\% lower in sun-facing (northerly exposed) habitats compared to more shaded (south-facing) rocks and declined with elevation. Gyrophoric acid concentration was positively correlated with the abundance and species richness of associated microarthropods, similar to the patterns found with lichen $\mathrm{N}$. This initial investigation indicates that there can be large intraspecific variation in lichen CBSC concentrations across relative short distances $(<500 \mathrm{~m})$ on Signy Island and raises further questions regarding current understanding of the role of CBSCs in Antarctic lichens in relation to biotic and abiotic pressures.
\end{abstract}

Keywords Exposure $\cdot$ Nitrogen $\cdot$ Invertebrate $\cdot$ Penguin $\cdot$ Usnea $\cdot$ Umbilicaria

This article belongs to the special issue on the "Pathways and impacts of biotically-mediated marine and other stored nutrient transfer between polar ecosystems", coordinated by Peter Convey, Katarzyna Zmudczyńska-Skarbek, and Stef Bokhorst.

Stef Bokhorst

s.f.bokhorst@vu.nl

1 Department of Ecological Science, Vrije Universiteit Amsterdam, De Boelelaan 1085, 1081 HV Amsterdam, The Netherlands

2 Faculty of Environmental Sciences and Natural Resource Management, Norwegian University of Life Sciences, P.O. Box 5003, 1432 Ås, Norway

3 British Antarctic Survey, Natural Environmental Research Council, High Cross, Madingley Road, Cambridge CB3 0ET, UK

\section{Introduction}

Lichens produce various carbon-based secondary compounds (CBSCs) which often vary in response to environmental gradients (Swanson et al. 1996; Bjerke et al. 2004; Vatne et al. 2011), in particular in relation to solar radiation (Bjerke et al. 2002; McEvoy et al. 2006, 2007), and nitrogen availability (Solhaug and Gauslaa 2012). In addition, CBSCs can affect lichen palatability for herbivores (Gauslaa 2005; Asplund and Wardle 2013). As one of the largest primary producer groups in Antarctica (Convey 2017), lichens have received considerable research attention addressing their abilities to cope with multiple environmental stresses, including low temperatures, desiccation and high solar radiation exposure (Schroeter et al. 1995; Kappen 2000; Lud et al. 2001; Gautam et al. 2011). However, data on intra-specific variation in lichen CBSCs across natural environmental light and nitrogen availability gradients is scarce in Antarctic habitats and their potential role in deterring herbivory has not been addressed. 
Temperature and water are the major constraints on life in the terrestrial domain of Antarctic ecosystems (Kennedy 1993; Convey et al. 2014). However, nutrients can become limiting, as is clear from biodiversity and ecosystem process rate increases in the vicinity of marine vertebrate concentrations that supply external nutrients from the ocean (Erskine et al. 1998; Ball et al. 2015; Bokhorst et al. 2019a). These aggregations generate volatilised ammonia which is then deposited further inland where the nitrogen is taken up by lichens and other primary producers (Crittenden et al. 2015; Bokhorst et al. 2019a). The direct uptake of marine-derived nitrogen by lichens is confirmed through the $\delta^{15} \mathrm{~N}$ isotopic signatures of the source and sink (Bokhorst et al. 2019b). Although lichen tissue nitrogen concentration is known to be affected by this nitrogen input from marine vertebrates it is currently unclear whether CBSC production in Antarctic lichens is affected.

Lichens growing under high nitrogen availability tend to have lower CBSC concentrations compared to species growing under nutrient-limited conditions in boreal forests (Solhaug and Gauslaa 2012) and experimental N-additions point toward similar responses (Hyvärinen et al. 2003). These patterns appear to be driven by an accumulation of photosynthates, as N-limitation restricts growth, which can result in an accumulation of phenolics or CBSC-like compounds. This carbon nutrient balance hypothesis (Bryant et al. 1983) or protein competition model (Jones and Hartley 1999) has also been applied to vascular plants and its effect has consequences for the activity and success of their associated herbivores (Estiarte et al. 1994; Grime et al. 1996). Whether lichens growing under the extreme environmental conditions of Antarctica are responsive to variation in nitrogen availability with respect to CBSC production, and if there are any potential consequences for associated invertebrates, are currently unknown.

As an initial investigation into influences on variation of lichen CBSC concentrations in Antarctic species along natural gradients of nitrogen availability and solar exposure, we here make use of an existing dataset on lichens with varying nitrogen concentrations (0.4-2.4\%) from Signy Island (South Orkney Islands, maritime Antarctic) (Bokhorst and Convey 2016). By quantifying the CBSC concentrations of previously sampled lichen tissue and comparing these between habitat solar exposure and along nitrogen gradients we aim to expand understanding of the adaptations displayed by Antarctic lichens along environmental gradients. As lichens with high $\mathrm{N}$-concentration also support higher abundance of associated invertebrates (Bokhorst and Convey 2016) we also set out to identify links between lichen CBSCs and lichen-invertebrate associations. We hypothesize that: (1) CBSC concentrations will be highest in lichens with north- rather than south-facing exposure due to higher solar radiation levels (Pintado et al. 1997; Bjerke et al. 2002;
Solhaug and Gauslaa 2012), and (2) CBSC concentrations will increase with distance to the coast along declining nitrogen gradients, similar to patterns reported for lichens in boreal regions between sites with high and low nitrogen loading (Hyvärinen et al. 2003; Solhaug and Gauslaa 2012). In line with the latter hypothesis, we expect that, (3) Microarthropod abundance may be negatively associated with lichen CBSC concentration along the nitrogen gradients.

\section{Methods}

We used a subset $(n=111)$ of lichen samples previously collected on Signy Island (South Orkney Islands, maritime Antarctic, $60^{\circ} 17^{\prime} \mathrm{S} 45^{\circ} 59^{\prime} \mathrm{W}$; Fig. 1), along transects with a gradient of nutrient availability away from marine vertebrate concentrations (penguin colonies; Bokhorst and Convey 2016). CBSCs in two common and widespread Antarctic lichens, Usnea antarctica $(n=72$ samples) and Umbilicaria antarctica $(n=39)$ were quantified. Both species produce melanin for light protection. Henceforth Usnea antarctica and Umbilicaria antarctica are referred to using their generic name alone. Signy Island has a mean annual temperature of c. $-2{ }^{\circ} \mathrm{C}$ and annual precipitation has rapidly risen from c. $400 \mathrm{~mm}$ to c. $1000 \mathrm{~mm}$ over recent decades, of which the majority is now rain rather than snow in summer (Walton 1982; Royles et al. 2012). The island has extensive cover of moss and lichen vegetation (Smith 1972; Cannone et al. 2017) and several large penguin colonies are located around its coast (Dunn et al. 2016).

For detailed description of the sampling regime see Bokhorst and Convey (2016). In brief, Usnea and Umbilicaria sampling was conducted at six different sites across the island. Three replicate parallel transects (Fig. 1), with 5 sampling points per transect, were established to sample lichens (15 samples per site for each species, with one site only having 4 sampling points). Each started at the coast near the edge of colonies of Adélie (Pygoscelis adeliae (Hombron \& Jacquinot)), chinstrap (P. antarctica Forster) or gentoo penguins ( $P$. papua Forster) and extended to a mountain top or glacier edge. In addition to these study transects, two sites beyond penguin influence were sampled in the interior of the island where Usnea was present but Umbilicaria was absent; one including an elevation gradient from a valley up a hill slope (Moraine Valley) and one across the highest hill tops of the island (North-South traverse). The influence of penguins on lichen $\mathrm{N}(\%)$ and associated microarthropod communities was assumed to be negligible when the $\mathrm{N}$ concentrations along the transect did not differ from the samples collected in the interior of the island (c. $0.7 \% \mathrm{~N}$; at $300-1500 \mathrm{~m}$ from the coast, depending on species). Sampling site exposure ranged across nearly all cardinal points (Table 1) and during 


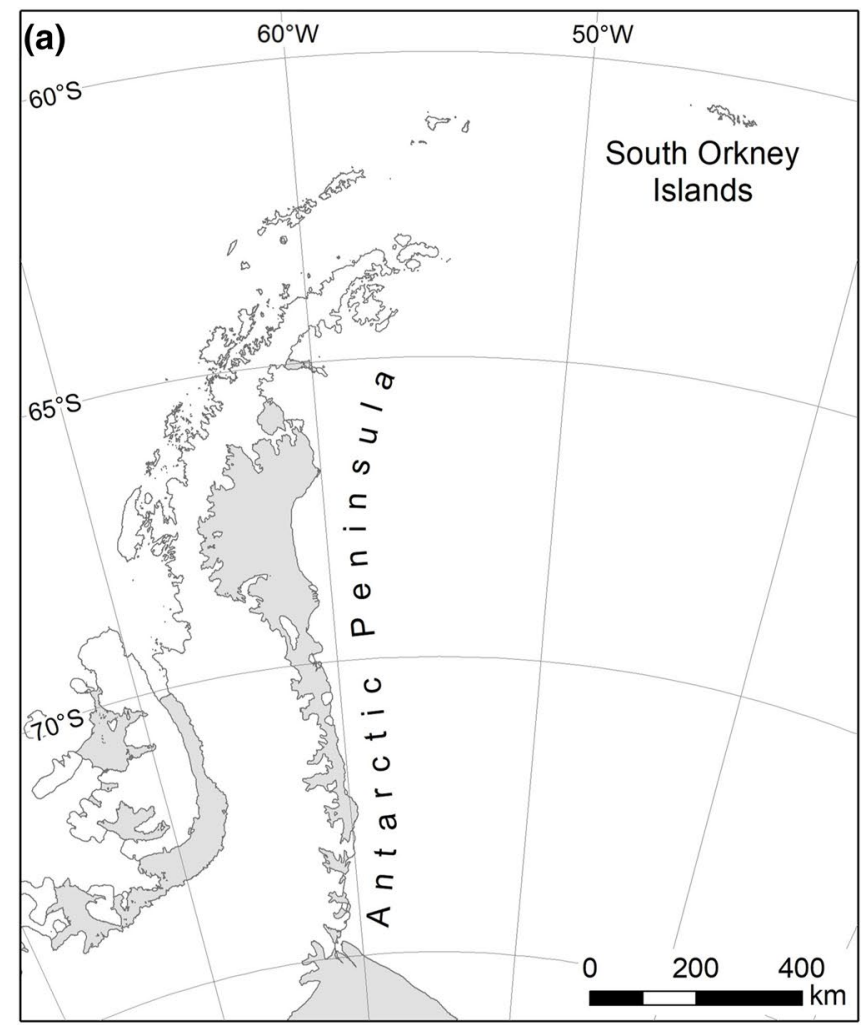

Fig. 1 Map of the Antarctic Peninsula and Signy Island (South Orkney Islands). a Antarctic Peninsula and the South Orkney Islands. b Major penguin colonies on Signy Island and transect lines along which samples of cryptogams and microarthropods were collected.

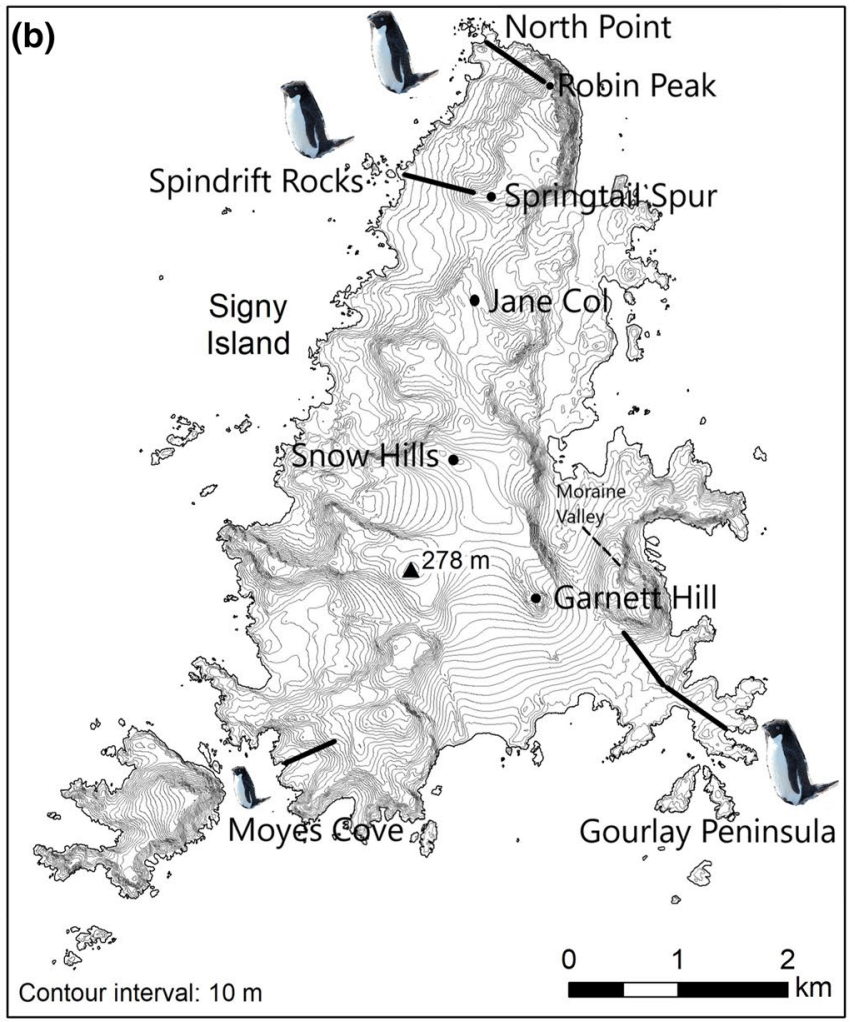

The dashed line represents a transect without penguin presence. The named solid circles represent the sampling points of the North-South traverse

Table 1 Sampling site information and chemical characteristics of Usnea antarctica and Umbilicaria antarctica collected at each site

\begin{tabular}{|c|c|c|c|c|c|c|c|c|}
\hline Site name & $\begin{array}{l}\text { Pen- } \\
\text { guins } \\
\text { present }\end{array}$ & Cardinal direction & Date & $\begin{array}{l}\text { Elevation range } \\
(\mathrm{m})\end{array}$ & $(n)$ & Nitrogen $(\%)$ & $\begin{array}{l}\text { Usnic acid (mg } \\
\left.\mathrm{g}^{-1} \mathrm{DW}\right)\end{array}$ & $\begin{array}{l}\text { Fumarprotocetraric } \\
\text { acid }\left(\mathrm{mg} \mathrm{g}^{-1} \mathrm{DW}\right)\end{array}$ \\
\hline & & & & & & \multicolumn{3}{|l|}{ Usnea antarctica } \\
\hline $\mathrm{N}-\mathrm{S}$ traverse & No & Top of hills & 16 & $160-265$ & 5 & $0.72(0.04) \mathrm{a}$ & $16.3(1.1) \mathrm{a}$ & $16.3(4.9) \mathrm{a}$ \\
\hline Moraine valley & No & $\mathrm{W}$ & 21 & 40-206 & 5 & $0.65(0.06) \mathrm{a}$ & $16.2(1.3) \mathrm{a}$ & $21.3(0.7) \mathrm{a}$ \\
\hline Moyes cove & Yes & S-W & 18 & $20-150$ & 4 & $1.32(0.10) \mathrm{b}$ & $15.3(0.7) \mathrm{a}$ & $2.1(1.4) b$ \\
\hline North point & Yes & $\mathrm{N}-\mathrm{W}$ & 9 & $30-200$ & 5 & $1.26(0.21) \mathrm{b}$ & $16.0(1.2) \mathrm{a}$ & $1.1(0.4) \mathrm{b}$ \\
\hline \multirow[t]{3}{*}{ Spindrift rocks } & Yes & $\mathrm{W}$ & 22 & $20-150$ & 5 & $1.10(0.12) b$ & $15.5(0.6) \mathrm{a}$ & $1.1(0.8) \mathrm{b}$ \\
\hline & & & & & & \multicolumn{3}{|c|}{ Umbilicaria antarctica } \\
\hline & & & & & & & \multicolumn{2}{|c|}{ Gyrophoric acid (mg g $\left.{ }^{-1} \mathrm{DW}\right)$} \\
\hline Gourlay Peninsula & Yes & S-E & 13 & $10-70$ & 5 & $1.35(0.12) \mathrm{a}$ & $10.2(0.9) \mathrm{a}$ & - \\
\hline Moyes cove & Yes & S-W & 18 & $20-150$ & 4 & $1.18(0.08) \mathrm{a}$ & $9.3(0.8) \mathrm{a}$ & - \\
\hline North point & Yes & $\mathrm{N}-\mathrm{W}$ & 23 & $30-200$ & 5 & $1.05(0.10) \mathrm{a}$ & $6.8(0.5) b$ & - \\
\hline
\end{tabular}

Date is the sampling day of December (2013) Values are mean of $(n)$ sampling points along each transect, with SE given in parentheses. Values with the same letter do not significantly differ (Tukey HSD $p<0.05$ ) within columns

lichen sampling we ensured that lichens were collected from rock surfaces facing the main cardinal direction of a given transect and not shaded by nearby boulders or rock faces. Elevation increased with distance along the transects
( $\left.r^{2}=0.92-0.99\right)$ by, on average, $22 \mathrm{~m} / 100 \mathrm{~m}$ except for Gourlay Peninsula and the North-South traverse where the elevation changed by $2-3 \mathrm{~m} / 100 \mathrm{~m}$ (Online Resource 1 ). 
Samples from within any of the six sites were collected on the same day. However, practical logistical constraints prevented sampling all sites on the same day, which we accept may affect CBSC concentration due to temporal changes in response to weather conditions (Bjerke et al. 2005; Gauslaa et al. 2013). Usnea was sampled between the 9th and 22nd of December 2013 while for Umbilicaria this was done between 13th and 23rd of December 2013 (Table 1). Although the time between sampling was limited we summarize the temperature and light conditions during sampling based on data from the Jane Col weather station (Convey et al. 2020), to identify if any major site differences between CBSC concentration could have been affected by sampling date. Mean daily air temperature rose from -5.4 to $-1.7{ }^{\circ} \mathrm{C}$ between 9 and 23 December 2013 (Online Resource 2). Mean daily solar radiation reached peak values (photosynthetic active radiation: 284-340 $\mu \mathrm{mol} \mathrm{m}^{-2} \mathrm{~s}^{-1}$ ) every 6-10 days with 'low' PAR levels of $128-256 \mu \mathrm{mol} \mathrm{m}{ }^{-2} \mathrm{~s}^{-1}$, due to cloud cover, in between. Sampling of Umbilicaria took place during cloudy days and we therefore anticipate no major differences in CBSC due to sampling date. Sampling of Usnea mostly took place during cloudy days, with the exception of one penguin affected site (Spindrift Rocks) and a site at the interior of the island (Moraine Valley) which took place on a sunny day and may therefore have resulted in higher CBSC concentration.

Dried and ground lichen samples were stored in the dark at room temperature, in Eppendorf tubes until CBSC analyses. Quantification of CBSCs in lichen tissue was performed during March 2015 and made following standardized methods (see Nybakken et al. 2007; Asplund and Wardle 2013) by extracting c. $30 \mathrm{mg}$ of ground lichen in acetone for three 45-min intervals. The combined supernatants were evaporated and re-dissolved in $2000 \mu \mathrm{L}$ acetone. Concentrations of CBSCs in the solution were quantified by high performance liquid chromatography (HPLC) using an ODS Hypersil column (Thermo Scientific, Waltham, MA, USA), $50 \times 4.6 \mathrm{~mm}$ using $0.25 \%$ orthophosphoric acid and $1.5 \%$ tetrahydrofuran in Millipore water (Millipore, Billerica, Massachusetts, USA) and 100\% methanol as mobile phases at $2 \mathrm{~mL} \mathrm{~min}{ }^{-1}$ and UV detection at $245 \mathrm{~nm}$. Compound identification was based on retention times and UV spectra from commercial standards. Both lichen species produce light-absorbing melanic compounds, which partly play similar roles as cortical CBSCs in lichens (i.e. light-protection). We did not attempt to quantify these compounds since they are difficult to extract from lichens. Instead previous studies have used indirect methods, e.g. measuring the browning reflectance index or applying or visually determining the colour (McEvoy et al. 2007; Gauslaa and Goward 2020). Measuring colour of the thin Usnea thalli would not be feasible.

\section{Statistical analyses}

One-way ANOVA was used to compare lichen N and CBSC concentrations among sampling sites using the sampling points along the transects $(n=5$, in one case $n=4)$ as replicates. We used linear regression to identify any significant changes in lichen nitrogen and CBSCs with distance to the coast for each sampling site separately and across penguin-affected and non-affected sites. We employed the 'relaimpo' package in R (Grömping 2006) and stepwise model selection by AIC (in both directions) using MASS (Venables and Ripley 2002), to identify the most likely variables to affect lichen CBSCs along the transects. However, multi-collinearity, assessed through the variance inflation factor using the mctest (Imdadullah et al. 2016) and FarrarGlauber F-test, remained a large feature among the explanatory variables. Principal component regression (Mevik and Wehrens 2007) was used to deal with multi-collinearity but the resulting components did not lead to a meaningful interpretation. Therefore, we calculated Pearson correlations for distance to the coast, cardinal direction of the growth site and elevation with lichen CBSC concentration using mean values across the transect sampling points at each site. Correlations between lichen $\mathrm{N}$, lichen thallus dry weight (g) and lichen CBSCs were calculated using individual lichen samples as replicates. In addition, we correlated microarthropod abundance and species richness data with site variables and lichen N and CBSC concentrations as above. For Usnea we analysed the data from penguin-affected and non-affected sites separately. Normality of data distribution was visually inspected through q-q plots and a Shapiro-Wilk test; log transformations were applied where appropriate and when this did not improve normality spearman correlations were applied. Analyses were performed using R (RCoreTeam 2015).

\section{Results}

\section{Usnea antarctica}

Fumarprotocetraric and usnic acids were the dominant CBSCs detected in Usnea. Fumarprotocetraric acid concentration was c. 13 times higher (Tukey HSD $p<0.05$ ) at inland sites (18.7 $\mathrm{mg} \mathrm{g}^{-1} \mathrm{DW}$ ) compared to sampling transects affected by penguins $\left(1.4 \mathrm{mg} \mathrm{g}^{-1} \mathrm{DW}\right)$ while usnic acid concentration did not differ between sites and were on average $15.87(\mathrm{SE} \pm 0.20) \mathrm{mg} \mathrm{g}^{-1} \mathrm{DW}$ (Table 1, Fig. 2). There was no effect of sampling date on the CBSC concentration between sites. Fumarprotocetraric and usnic acid concentrations did not significantly change along the nitrogen gradients (Fig. 2b, c, Table 2, Online Resource 1). Nitrogen concentration of Usnea was on average twice as high when 

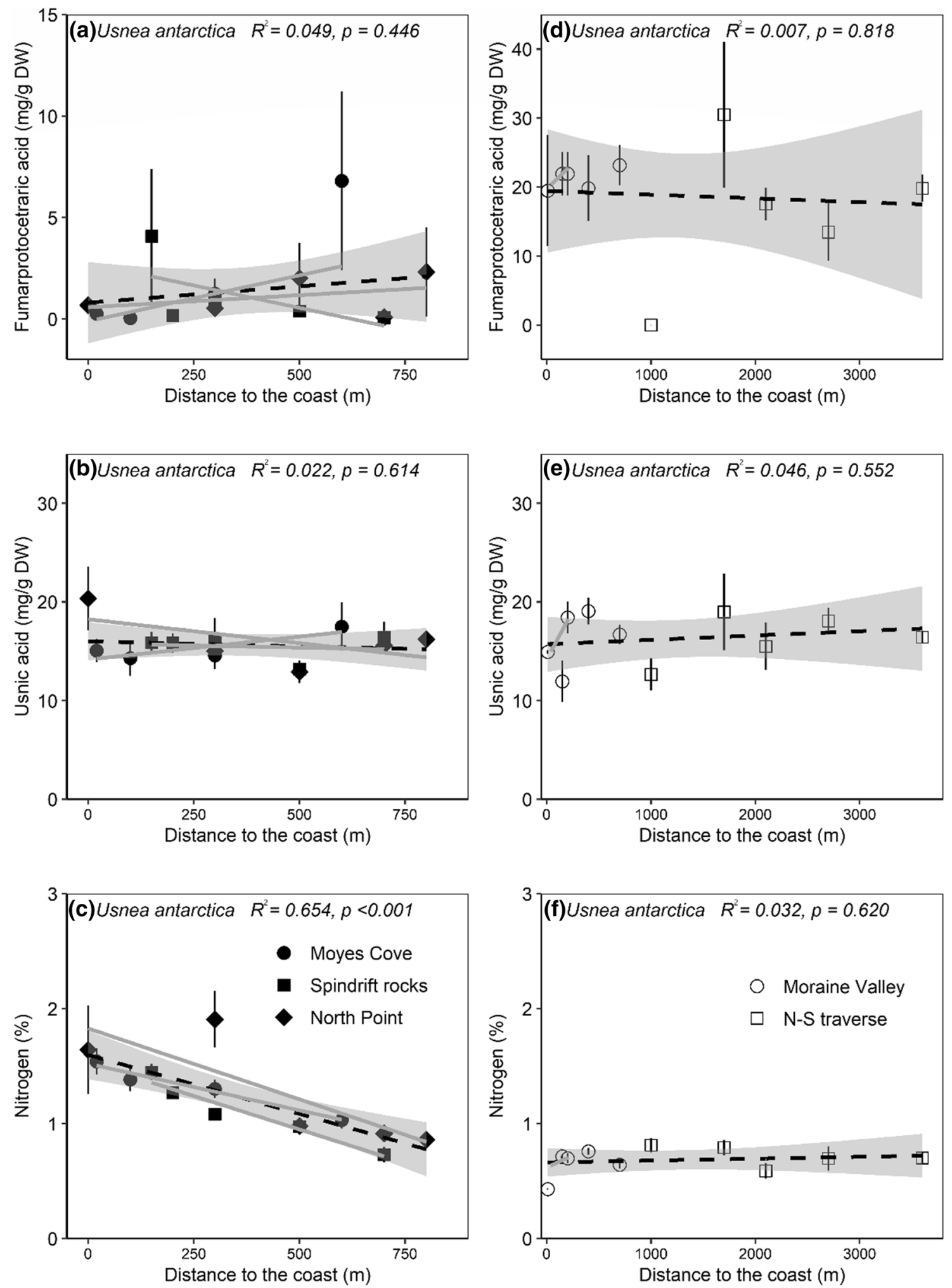

Fig. 2 Concentrations of carbon-based secondary compounds and nitrogen in Usnea antarctica along transects from the coast inland influenced by penguins $(\mathbf{a}-\mathbf{c} ; n=14)$ and sites beyond the influence of penguins $(\mathbf{d}-\mathbf{f} ; n=10)$. Data points are mean of 3 replicate samples with SE as error bars. Grey lines represent individual transect regres-

sions while the overall regression is shown by the dashed black line. $95 \%$ confidence intervals are shown by grey shading. Note the differences in scaling for $\mathbf{a}$ and $\mathbf{d}$. Regression coefficients of the change along each transect are presented in Online Resource 1 
Table 2 Correlation coefficients of lichen carbon based secondary compounds across distance, cardinal direction and elevation and with lichen nitrogen for Usnea antarctica and Umbilicaria antarctica along various transects with (+) and without penguin-influence (-) on Signy Island

\begin{tabular}{|c|c|c|c|c|c|}
\hline \multirow[b]{3}{*}{ Penguin presence } & \multicolumn{4}{|l|}{ Usnea } & \multirow{3}{*}{$\begin{array}{l}\text { Umbilicaria } \\
\text { Gyrophoric acid } \\
+(\mathrm{df}=12)\end{array}$} \\
\hline & \multicolumn{2}{|l|}{ Usnic acid } & \multicolumn{2}{|c|}{ Fumarprotocetraric acid } & \\
\hline & $+(\mathrm{df}=12)$ & $-(\mathrm{df}=8)$ & $+(\mathrm{df}=12)$ & $-(\mathrm{df}=8)$ & \\
\hline Distance to the coast & -0.148 & 0.214 & 0.222 & -0.084 & -0.242 \\
\hline Cardinal direction & 0.152 & 0.023 & -0.205 & -0.333 & $-0.579 *$ \\
\hline \multirow[t]{2}{*}{ Elevation } & -0.020 & 0.056 & 0.253 & -0.289 & -0.516 \\
\hline & $(\mathrm{df}=40)$ & $(\mathrm{df}=28)$ & $(\mathrm{df}=40)$ & $(\mathrm{df}=28)$ & $(\mathrm{df}=37)$ \\
\hline Lichen nitrogen & $0.080^{\times}$ & 0.104 & $0.130^{\times}$ & -0.167 & 0.263 \\
\hline Lichen sample biomass & $0.120^{\times}$ & 0.139 & $-0.180^{\times}$ & $0.363 *$ & 0.129 \\
\hline
\end{tabular}

Regression coefficients for distance, cardinal direction and elevation were based on sampling point means while correlations with lichen nitrogen and sample biomass were based on individual lichen samples

$d f$ degrees of freedom

$* p<0.05, * * p<0.01, * * * p<0.001$

$\times$ Spearman's rank correlation rho

growing close to penguin colonies $(1.23 \%)$ compared to samples obtained at greater distance $(>400 \mathrm{~m})$ and those clearly outside the influence of penguins $(0.69 \%)$ (Table 1 , Fig. 2c, f).

There were no significant correlations of CBSC concentrations with any of the explanatory variables measured (Table 2). Among the Usnea samples collected at the inland sites there was a positive correlation $\left(R^{2}=0.116, p=0.049\right.$, $n=28$ ) between lichen thallus dry weight and usnic acid concentration. There were also no significant correlations of CBSCs with the microarthropods associated with Usnea (Online Resource 3 and 4). Microarthropod abundance was positively correlated ( $r=0.318, p<0.01$ ) with lichen N concentration across the whole Usnea dataset (Online Resources 3 and 4). However, this correlation disappeared when analysed for penguin-affected and non-affected sites separately (Table 3). Microarthropods species richness was positively correlated ( $r=0.700, p<0.001)$ with lichen $\mathrm{N}$ concentration across the whole data set (Online Resource 3 and 4) and for the penguin affected sites separately (Table 3). Species
Table 3 Correlation coefficients of micro-arthropod abundance and species richness $(\mathrm{R})$ with distance to the coast, cardinal direction, elevation and lichen nitrogen and specific carbon based secondary compounds for Usnea antarctica and Umbilicaria antarctica along various transects with (+) and without penguin-influence (-) on Signy Island

\begin{tabular}{|c|c|c|c|c|c|c|}
\hline \multirow[b]{3}{*}{ Penguins presencet } & \multicolumn{4}{|l|}{ Usnea } & \multicolumn{2}{|l|}{ Umbilicaria } \\
\hline & \multicolumn{2}{|l|}{ Abundance } & \multicolumn{2}{|l|}{$\mathrm{R}$} & \multirow{2}{*}{$\begin{array}{l}\text { Abundance } \\
+(\mathrm{df}=12)\end{array}$} & \multirow{2}{*}{$\begin{array}{l}\mathrm{R} \\
+(\mathrm{df}=12)\end{array}$} \\
\hline & $+(\mathrm{df}=12)$ & $-(\mathrm{df}=8)$ & $+(\mathrm{df}=12)$ & $-(\mathrm{df}=8)$ & & \\
\hline Distance to the coast & -0.201 & -0.191 & $-0.915 * * *$ & -0.309 & -0.504 & $-0.691 * *$ \\
\hline Cardinal direction & 0.087 & -0.041 & -0.015 & -0.196 & -0.447 & -0.262 \\
\hline \multirow[t]{2}{*}{ Elevation } & -0.162 & -0.111 & $-0.889 * * *$ & -0.277 & -0.468 & $-0.483^{\prime}$ \\
\hline & $(\mathrm{df}=40)$ & $(\mathrm{df}=28)$ & $(\mathrm{df}=40)$ & $(\mathrm{df}=28)$ & $(\mathrm{df}=37)$ & $(\mathrm{df}=37)$ \\
\hline Lichen nitrogen & 0.029 & 0.166 & $0.682 * * * \times$ & $0.019^{\times}$ & $0.370 * *$ & $0.519 * * *$ \\
\hline Usnic acid & 0.046 & 0.208 & 0.099 & 0.212 & & \\
\hline Fumarprotocetraric acid & -0.022 & 0.249 & -0.178 & 0.253 & & \\
\hline Gyrophoric acid & & & & & $0.613 * * *$ & $0.493 * *$ \\
\hline
\end{tabular}

Correlation coefficients for distance, cardinal direction and elevation were based on sampling point means while correlations with lichen nitrogen and sample biomass were based on individual lichen samples

$d f$ degrees of freedom

${ }^{*} p<0.05, * * p<0.01, * * * p<0.001$

${ }^{\times}$Spearman's rank correlation rho 
richness correlated negatively with distance to the coast and elevation at the penguin affected sites (Table 3).

\section{Umbilicaria antarctica}

The dominant CBSC measured in Umbilicaria was gyrophoric acid. This declined with elevation and was on average 33\% higher when facing south-east (Gourlay Peninsula) compared to north-west exposure (North Point; Tables 1,2). Mean gyrophoric acid concentration did not change significantly with distance to penguin colonies while $\mathrm{N}$ concentra-

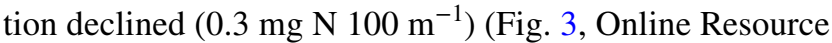
$1)$. However, there were declines $(p<0.05)$ in gyrophoric acid concentration at Gourlay Peninsula $\left(0.24 \mathrm{mg}_{\left.100 \mathrm{~m}^{-1}\right)}\right.$ and Moyes Cove $\left(0.85 \mathrm{mg} 100 \mathrm{~m}^{-1}\right)$. Nitrogen concentration of Umbilicaria was on average twice as high when growing close to penguin colonies $(1.50 \%)$ than at greater distance $(0.75 \%$ at $>600 \mathrm{~m})$.

Microarthropod abundance and species richness were positively correlated with lichen $\mathrm{N}$ and gyrophoric acid concentration of Umbilicaria and negatively with distance to the coast, cardinal direction and elevation (Table 3, Fig. 4).

\section{Discussion}

There was great variability in the CBSC concentrations measured in Usnea and Umbilicaria, but their intra-specific variation in relation to habitat exposure and nitrogen gradients did not support our hypotheses. The variability in CBSC concentrations in relation to the measured environmental conditions indicates that other factors may play a role, or that multiple factors act simultaneously to induce CBSC production (Bjerke et al. 2004). Such high phenotypic plasticity in lichen CBSC in relation to environmental conditions has been reported in the High Arctic Svalbard archipelago (Bjerke et al. 2004) and highlights a need for further experimental studies and accurate environmental monitoring at appropriate physical scales (Convey et al. 2018) in order to better understand how Antarctic lichens will cope with future changes in microhabitat conditions, nutrient availability and potential herbivory due to climate change and biotic pressures from invasive species (Convey and Peck 2019).

There was no support within the dataset for the hypothesis that lichens with greater exposure to solar radiation (i.e. north-facing) would have greater CSBC concentrations, as none of the lichen CBSC concentrations responded consistently between the contrasting north- and south-exposed sampling sites. Thallus coloration often changes visibly between lichens growing in full sunlight and in shaded habitats, which is often driven by associated changes in CBSC concentrations (Kappen 1983; Solhaug et al. 2009; Solhaug and Gauslaa 2012). Usnic acid, which is deposited in the
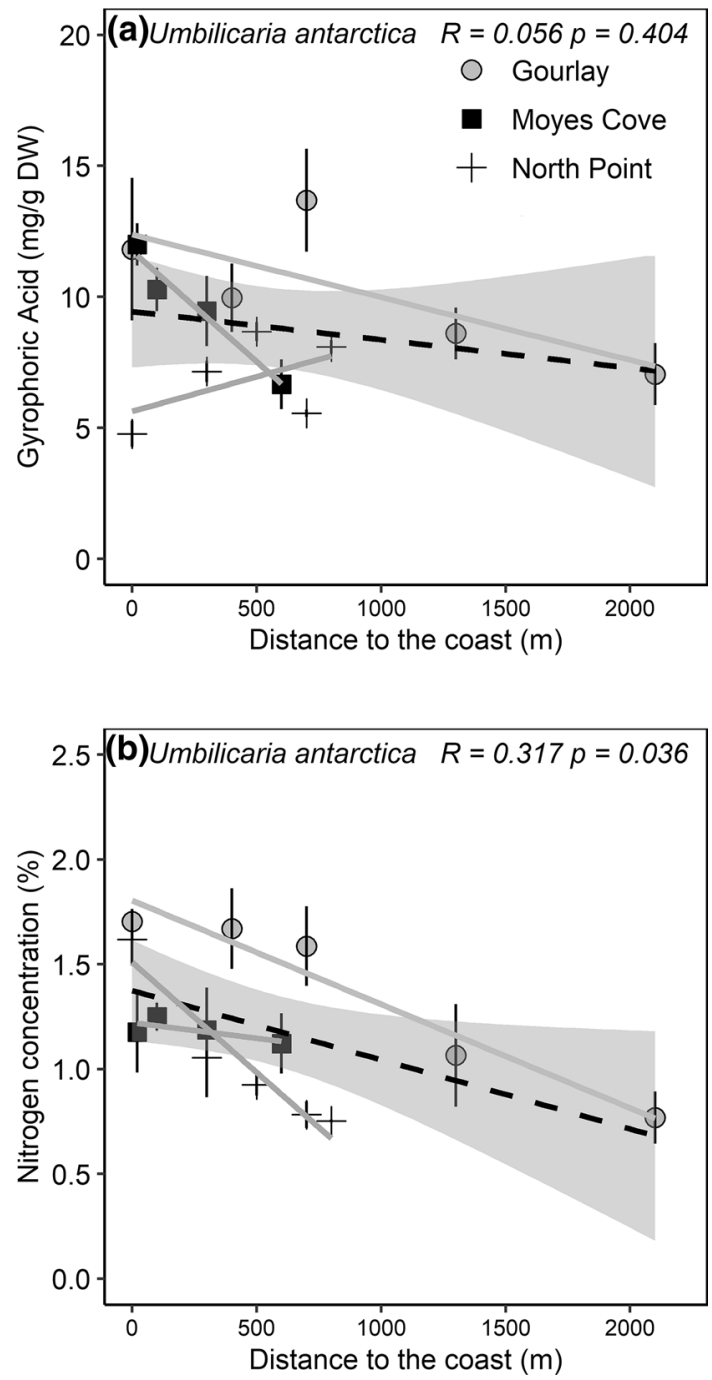

Fig. 3 Concentrations of carbon-based secondary compounds and nitrogen in Umbilicaria antarctica along transects from the coast inland influenced by penguins. Data points are mean of 3 replicate samples with SE as error bars $(n=14)$. Grey lines represent individual transect regressions while the overall regression is shown by the dashed black line with $95 \%$ confidence intervals is shown by grey shading. $R^{2}$ and $p$ value of the overall regression is presented on each figure. Regression coefficients of the change along each transect are presented in Online Resource 1

thallus cortex, is induced when Usnea sp. are transplanted across light gradients in northern boreal forests (Nybakken et al. 2007). It is possible that the high ambient summer solar radiation levels (PAR and UV) and lack of shading by vascular plants in Antarctica induce high background concentrations of usnic acid in Usnea that override the differences in light regimes between north- and south-facing habitats or that the compound's production is induced by multiple factors (Bjerke et al. 2002, 2004). Further, both species produce melanin, which absorb light and thus reduce the need for phenolic light-screeners (Gauslaa and Solhaug 

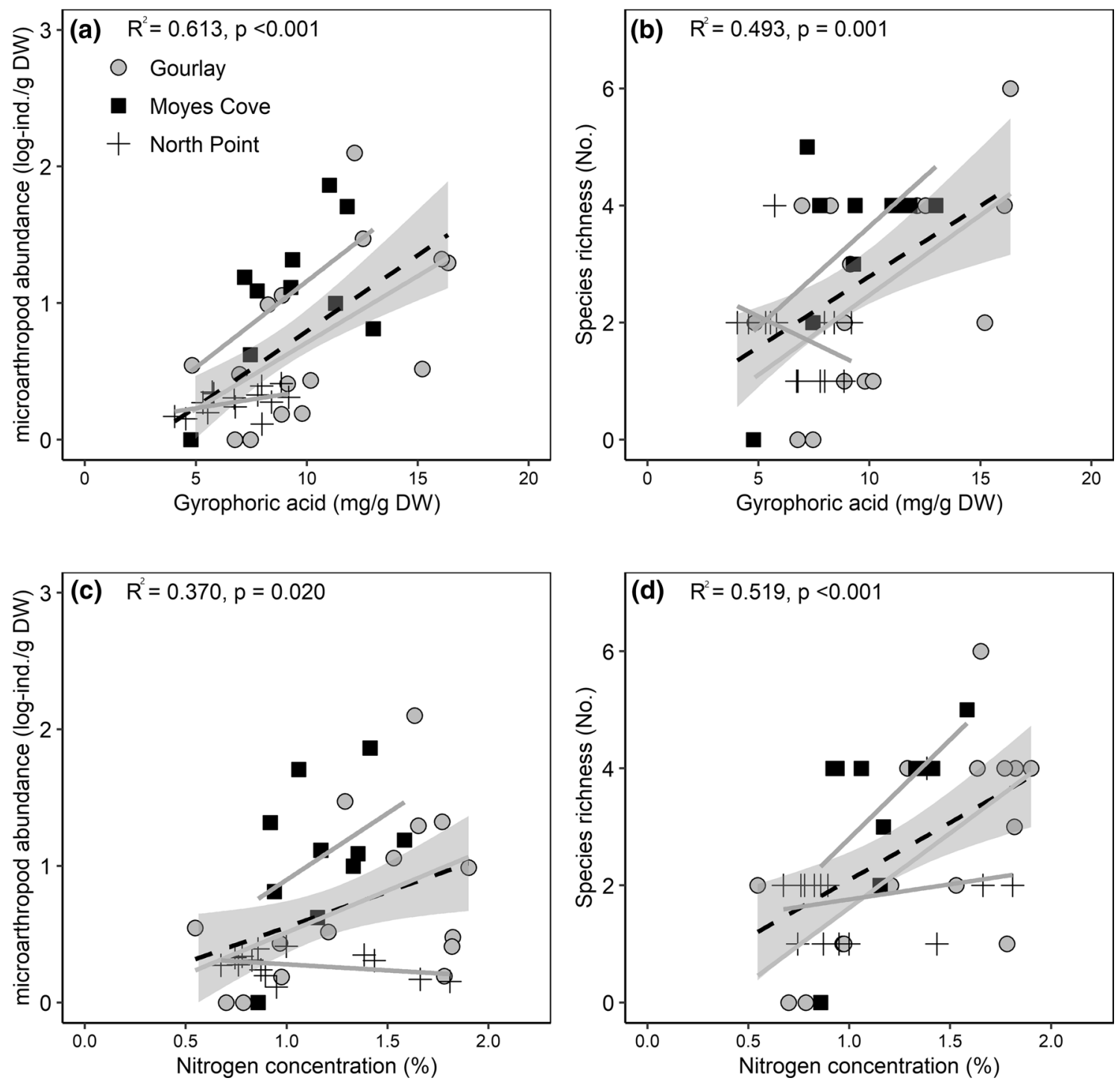

Fig. 4 Relationship between gyrophoric acid concentration $(\mathbf{a}, \mathbf{b})$ and nitrogen concentration (c, d) of Umbilicaria antarctica with microarthropod abundance and species richness. Data points are individual lichen samples $(n=39)$ collected along transects away from penguin

2001; Asplund et al. 2021). As such, the lack of response in usnic acid could also be due to sufficient light protection from melanic compounds. Gyrophoric acid concentration in Umbilicaria was higher at south-facing, more shaded, sites compared with north-facing. However, as this CBSC is mainly restricted to the medulla its unlikely to function as a light-screener (Solhaug and Gauslaa 2012). The observed decline of gyrophoric acid with elevation is consistent with CBSC declines along elevation gradients in southern Norway (Vatne et al. 2011). Other reports show no effect of elevation (Bidussi et al. 2013), as found for usnic acid here, indicating that the response is highly species- and contextdependent (Bjerke et al. 2004). Alternatively, morphological adaptations may have played a stronger role in protection

colonies. Grey lines represent individual transect correlations while the overall correlation is shown by the dashed black line with $95 \%$ confidence intervals shown by grey shading

against sunlight (Pintado et al. 1997). The data presented here indicate that the CBSC concentrations of both Usnea and Umbilicaria growing on north-facing rocks where they are periodically exposed to full sunlight are equivalent to those growing in more shaded habitats on this maritime Antarctic island.

Lichens growing in habitats with high nitrogen availability tend to produce less CBSCs than those growing in nutrient-poor environments (Solhaug and Gauslaa 2012), consistent with the carbon nutrient balance hypothesis (Bryant et al. 1983). However, these studies were based on inter-specific comparisons, while intra-specific variation in lichen responses to nitrogen availability has received limited attention (but see Munzi et al. 2017a). Experimental 
nitrogen additions to lichen induced reductions in usnic acid concentration in Cladonia stellaris (Hyvärinen et al. 2003) and total CBSC concentration of Platismatia glauca, while various other lichens were unresponsive in a boreal forest ecosystem (Nybakken et al. 2009). Usnea did not show consistent patterns in CBSC concentration along the marine vertebrate-associated nitrogen gradients on Signy Island, despite $\mathrm{N}$-tissue concentrations being equivalent or sometimes higher than reported from experimental treatments where changes in CBSC concentrations have been reported (Hyvärinen et al. 2003). Fumarprotocetraric acid concentration in Usnea was 13 times higher at sites beyond the $\mathrm{N}$-influence of penguin colonies (Table 1), but it is unlikely that nitrogen played a key role here as a gradual change in CBSC concentration would then have been expected with progression along the nitrogen gradient. Changes in gyrophoric acid concentrations in Umbilicaria appear to be linked to the changes along the marine vertebrate influenced gradients, but do not provide support for our second hypotheses as there was no consistent pattern in CBSC concentration with lichen-N (Table 2). It seems unlikely that these lichens are insensitive to the nitrogen gradients associated with proximity to marine vertebrate colonies and there may, therefore, be additional adaptations, such as in use of metabolic pathways (Hogan et al. 2010; Crittenden et al. 2015; Munzi et al. 2017b), chitin accumulation (Munzi et al. 2017a) and morphological features, which could have suppressed or hidden any CBSC response.

\section{Lichen-invertebrate associations}

Lichen CBSCs have been shown to inhibit grazer activity in experimental studies where the CBSCs were washed out and grazing or abundance of associated invertebrates was then compared to non-washed lichens (Asplund 2011; Asplund and Wardle 2013; Asplund et al. 2015). However, within the current dataset, there is no suggestion that CBSCs produced by Usnea play an anti-herbivory role towards Antarctic microarthropods. Gyrophoric acid concentration in Umbilicaria correlated with microarthropod abundance and richness, which may indicate a causal connection. The high microarthropod abundance found among nutrient rich Umbilicaria could have resulted in grazing-induced gyrophoric acid production, which would explain the lack of consistent correlation between lichen nitrogen and CBSC concentration (Table 2) as expected from the carbon nutrient balance hypothesis. Experimental approaches, such as grazing trials with acetone washed lichen thalli (Solhaug and Gauslaa 2001; Asplund et al. 2015), may provide further insights into the role of CBSCs in Antarctic lichen-invertebrate associations.

The data presented here showed large intra-specific changes in lichen CBSC concentrations across relatively short distances $(<500 \mathrm{~m})$ that did not match with the hypothesised outcomes relating to light regime, the carbon nutrient balance hypothesis (Bryant et al. 1983) or grazing pressure (Solhaug and Gauslaa 2012). It remains possible that the CBSCs found in Usnea and Umbilicaria were the result of a combination of factors, such as micro-climate of the lichen habitat, temporal variability in production rates, production of additional compounds, such as melanin, that may provide similar functions as CBSCs and morphological adaptations. Considering that lichens are one of the major primary producers in Antarctic terrestrial ecosystems (Convey 2017), and the effects that lichen CBSCs can have on other trophic levels and ecosystem carbon and nutrient cycling as reported in various ecosystems (Cornelissen et al. 2007; Asplund and Wardle 2013), further work is required to elucidate how habitat conditions, associated micro-climate and other trophic levels interact in shaping lichen-dominated ecosystems in Antarctica.

Supplementary Information The online version contains supplementary material available at https://doi.org/10.1007/s00300-021-02839-y.

Acknowledgements This work would not have been possible without the logistical support of the British Antarctic Survey. Fieldwork for SB was supported by an Antarctic Science Bursary. PC is supported by Natural Environment Research Council core funding to the British Antarctic Survey 'Biodiversity, Evolution and Adaptation' team. We would like to thank the reviewers for their constructive comments that improved this manuscript.

Author contributions SB and PC conceived and designed the research. SB conducted the field sampling and JA performed the laboratory analyses of lichen CBSCs. All authors contributed to the writing of the manuscript.

Data availability The datasets generated during and/or analysed during the current study are available from the corresponding author on reasonable request.

\section{Declarations}

Conflict of interest The authors have no conflicts of interest to declare that are relevant to the content of this article.

Ethical approval No approval of research ethics committees was required to accomplish the goals of this study because experimental work was conducted with unregulated lichen species.

Open Access This article is licensed under a Creative Commons Attribution 4.0 International License, which permits use, sharing, adaptation, distribution and reproduction in any medium or format, as long as you give appropriate credit to the original author(s) and the source, provide a link to the Creative Commons licence, and indicate if changes were made. The images or other third party material in this article are included in the article's Creative Commons licence, unless indicated otherwise in a credit line to the material. If material is not included in the article's Creative Commons licence and your intended use is not permitted by statutory regulation or exceeds the permitted use, you will 
need to obtain permission directly from the copyright holder. To view a copy of this licence, visit http://creativecommons.org/licenses/by/4.0/.

\section{References}

Asplund J (2011) Snails avoid the medulla of Lobaria pulmonaria and L. scrobiculata due to presence of secondary compounds. Fungal Ecol 4:356-358. https://doi.org/10.1016/j.funeco.2011.05.002

Asplund J, Wardle DA (2013) The impact of secondary compounds and functional characteristics on lichen palatability and decomposition. J Ecol 101:689-700

Asplund J, Bokhorst S, Kardol P, Wardle DA (2015) Removal of secondary compounds increases invertebrate abundance in lichens. Fungal Ecol 18:18-25. https://doi.org/10.1016/j.funeco.2015. 07.009

Asplund J et al (2021) Contrasting responses of plant and lichen carbon-based secondary compounds across an elevational gradient. Funct Ecol. https://doi.org/10.1111/1365-2435.13712

Ball BA, Tellez CR, Virginia RA (2015) Penguin activity influences soil biogeochemistry and soil respiration in rookeries on Ross Island, Antarctica. Polar Biol 38:1357-1368. https://doi.org/10. 1007/s00300-015-1699-7

Bidussi M, Goward T, Gauslaa Y (2013) Growth and secondary compound investments in the epiphytic lichens Lobaria pulmonaria and Hypogymnia occidentalis transplanted along an altitudinal gradient in British Columbia. Botany 91:621-630. https://doi. org/10.1139/cjb-2013-0088

Bjerke JW, Lerfall K, Elvebakk A (2002) Effects of ultraviolet radiation and PAR on the content of usnic and divaricatic acids in two arctic-alpine lichens. Photochem Photobiol Sci 1:678-685. https://doi.org/10.1039/B203399B

Bjerke JW, Joly D, Nilsen L, Brossard T (2004) Spatial trends in usnic acid concentrations of the lichen Flavocetraria nivalis along local climatic gradients in the Arctic (Kongsfjorden, Svalbard). Polar Biol 27:409-417. https://doi.org/10.1007/ s00300-004-0590-8

Bjerke JW, Elvebakk A, Domínguez E, Dahlback A (2005) Seasonal trends in usnic acid concentrations of Arctic, alpine and Patagonian populations of the lichen Flavocetraria nivalis. Phytochemistry 66:337-344. https://doi.org/10.1016/j.phytochem.2004.12.007

Bokhorst S, Convey P (2016) Impact of marine vertebrates on Antarctic terrestrial micro-arthropods. Antarct Sci 28:175-186. https://doi. org/10.1017/s0954102015000607

Bokhorst S, Convey P, Aerts R (2019a) Nitrogen inputs by marine vertebrates drive abundance and richness in Antarctic terrestrial ecosystems. Curr Biol 29:1721-1727. https://doi.org/10.1016/j. cub.2019.04.038

Bokhorst S, van Logtestijn R, Convey P, Aerts R (2019b) Nitrogen isotope fractionation explains the N-15 enrichment of Antarctic cryptogams by volatilized ammonia from penguin and seal colonies. Polar Res. https://doi.org/10.33265/polar.v38.3355

Bryant JP, Chapin FS, Klein DR (1983) Carbon/nutrient balance of boreal plants in relation to vertebrate herbivory. Oikos 40:357368. https://doi.org/10.2307/3544308

Cannone N, Dalle Fratte M, Convey P, Worland MR, Guglielmin M (2017) Ecology of moss banks on Signy Island (maritime Antarctic). Bot J Linn Soc 184:518-533. https://doi.org/10.1093/botli nnean/box040

Convey P (2017) Antarctic ecosystems. In: Levin SA (ed) Reference module in life sciences. Elsevier, Amsterdam, pp 179-188. https:// doi.org/10.1016/B978-0-12-809633-8.02182-8
Convey P et al (2014) The spatial structure of Antarctic biodiversity. Ecol Monogr 84:203-244. https://doi.org/10.1890/12-2216.1

Convey P, Coulson SJ, Worland MR, Sjöblom A (2018) The importance of understanding annual and shorter-term temperature patterns and variation in the surface levels of polar soils for terrestrial biota. Polar Biol. https://doi.org/10.1007/s00300-018-2299-0

Convey P, Newsham K, Geissler P, Massey A, Jobson M (2020) Microclimate data from Jane Col, 2007-2016. https://doi.org/10.5285/ 5c380c93-986e-499c-b09f-25939daf4766

Convey P, Peck LS (2019) Antarctic environmental change and biological responses. Sci Adv 5:0888. https://doi.org/10.1126/sciadv. aaz0888

Cornelissen JHC, Lang SI, Soudzilovskaia NA, During HJ (2007) Comparative cryptogam ecology: a review of bryophyte and lichen traits that drive biogeochemistry. Ann Bot 99:987-1001. https://doi.org/10.1093/aob/mcm030

Crittenden PD, Scrimgeour CM, Minnullina G, Sutton MA, Tang YS, Theobald MR (2015) Lichen response to ammonia deposition defines the footprint of a penguin rookery. Biogeochemistry 122:295-311. https://doi.org/10.1007/s10533-014-0042-7

Dunn MJ, Jackson JA, Adlard S, Lynnes AS, Briggs DR, Fox D, Waluda CM (2016) Population size and decadal trends of three penguin species nesting at Signy Island, South Orkney Islands. PLoS ONE 11:e0164025. https://doi.org/10.1371/journal.pone. 0164025

Erskine PD, Bergstrom DM, Schmidt S, Stewart GR, Tweedie CE, Shaw JD (1998) Subantarctic Macquarie Island-a model ecosystem for studying animal-derived nitrogen sources using N-15 natural abundance. Oecologia 117:187-193. https://doi.org/10. $1007 / \mathrm{s} 004420050647$

Estiarte M, Filella I, Serra J, Penuelas J (1994) Effects of nutrient and water-stres on leaf phenolic content of peppers and susceptibility to generalist herbivore Helicoverpa armigera (Hubner). Oecologia 99:387-391. https://doi.org/10.1007/bf00627753

Gauslaa Y (2005) Lichen palatability depends on investments in herbivore defence. Oecologia 143:94-105

Gauslaa Y, Solhaug KA (2001) Fungal melanins as a sun screen for symbiotic green algae in the lichen Lobaria pulmonaria. Oecologia 126:462-471. https://doi.org/10.1007/s004420000541

Gauslaa Y, Goward T (2020) Melanic pigments and canopy-specific elemental concentration shape growth rates of the lichen Lobaria pulmonaria in unmanaged mixed forest. Fungal Ecol 47:100984. https://doi.org/10.1016/j.funeco.2020.100984

Gauslaa Y, Bidussi M, Solhaug KA, Asplund J, Larsson P (2013) Seasonal and spatial variation in carbon based secondary compounds in green algal and cyanobacterial members of the epiphytic lichen genus Lobaria. Phytochemistry 94:91-98. https://doi.org/10. 1016/j.phytochem.2013.04.003

Gautam S, Singh J, Pant AB (2011) Effect of UV-B radiations on the pigments of two Antarctic lichens of Schirmacher Oasis, East Antarctica. Pol Polar Res 32:279-287. https://doi.org/10.2478/ v10183-011-0019-3

Grime JP, Cornelissen JHC, Thompson K, Hodgson JG (1996) Evidence of a causal connection between anti-herbivore defence and the decomposition rate of leaves. Oikos 77:489-494

Grömping U (2006) relative importance for linear regression in R: the package relaimpo. J Stat Softw 17:1-27

Hogan EJ, Minnullina G, Smith RI, Crittenden PD (2010) Effects of nitrogen enrichment on phosphatase activity and nitrogen:phosphorus relationships in Cladonia portentosa. New Phytol 186:911-925. https://doi.org/10.1111/j.1469-8137.2010. 03222.x

Hyvärinen M, Walter B, Koopmann R (2003) Impact of fertilisation on phenol content and growth rate of Cladina stellaris: a test of the carbon-nutrient balance hypothesis. Oecologia 134:176-181. https://doi.org/10.1007/s00442-002-1105-3 
Imdadullah M, Aslam M, Altaf S (2016) mctest: an R package for detection of collinearity among regressors. $\mathrm{R} \mathrm{J} \mathrm{8:495-505}$

Jones CG, Hartley SE (1999) A protein competition model of phenolic allocation. Oikos 86:27-44. https://doi.org/10.2307/3546567

Kappen L (1983) Ecology and physiology of the Antarctic fruticose lichen Usnea sulphurea (Koenig) Th. Fries Polar Biol 1:249-255

Kappen L (2000) Some aspects of the great success of lichens in Antarctica. Antarct Sci 12:314-324

Kennedy AD (1993) Water as a limiting factor in the Antarctic terrestrial environment-a biogeographical synthesis. Arct Alp Res 25:308-315

Lud D, Huiskes AHL, Moerdijk TCW, Rozema J (2001) The effects of altered levels of UV-B radiation on an Antarctic grass and lichen. Plant Ecol 154:87-99

McEvoy M, Nybakken L, Solhaug KA, Gauslaa Y (2006) UV triggers the synthesis of the widely distributed secondary lichen compound usnic acid. Mycol Prog 5:221-229. https://doi.org/10. 1007/s11557-006-0514-9

McEvoy M, Gauslaa Y, Solhaug KA (2007) Changes in pools of depsidones and melanins, and their function, during growth and acclimation under contrasting natural light in the lichen Lobaria pulmonaria. New Phytol 175:271-282. https://doi.org/10.1111/j. 1469-8137.2007.02096.x

Mevik B-H, Wehrens R (2007) The pls package: principal component and partial least squares regression in R. J Stat Softw 2007(18):23. https://doi.org/10.18637/jss.v018.i02

Munzi S, Cruz C, Maia R, Máguas C, Perestrello-Ramos MM, Branquinho $C$ (2017a) Intra- and inter-specific variations in chitin in lichens along a N-deposition gradient. Environ Sci Pollut Res 24:28065-28071. https://doi.org/10.1007/s11356-017-0378-3

Munzi S et al (2017b) The cost of surviving nitrogen excess: energy and protein demand in the lichen Cladonia portentosa as revealed by proteomic analysis. Planta 245:819-833. https://doi.org/10. 1007/s00425-017-2647-2

Nybakken L, Asplund J, Solhaug KA, Gauslaa Y (2007) Forest successional stage affects the cortical secondary chemistry of three old forest lichens. J Chem Ecol 33:1607-1618. https://doi.org/10. 1007/s10886-007-9339-5

Nybakken L, Johansson O, Palmqvist K (2009) Defensive compound concentration in boreal lichens in response to simulated nitrogen deposition. Glob Change Biol 15:2247-2260. https://doi.org/10. 1111/j.1365-2486.2009.01853.x

Pintado A, Valladares F, Sancho LG (1997) Exploring phenotypic plasticity in the lichen Ramalina capitata: Morphology, water relations and chlorophyll content in north- and south-facing populations. Ann Bot 80:345-353
RCoreTeam (2015) R: a language and environment for statistical computing. R Foundation for Statistical Computing, Vienna

Royles J, Ogée J, Wingate L, Hodgson DA, Convey P, Griffiths $\mathrm{H}$ (2012) Carbon isotope evidence for recent climate-related enhancement of $\mathrm{CO}_{2}$ assimilation and peat accumulation rates in Antarctica. Glob Change Biol 18:3112-3124. https://doi.org/10. 1111/j.1365-2486.2012.02750.x

Schroeter B, Olech M, Kappen L, Heitland W (1995) Ecophysiological investigations of Usnea antarctica in the Maritime Antarctic. 1. Annual microclimatic conditions and potential primary production. Antarct Sci 7:251-260

Smith RIL (1972) Vegetation of the South Orkney Islands with particular reference to Signy Island. British Antarctic Survey Scientific Reports 68

Solhaug KA, Gauslaa Y (2001) Acetone rinsing-a method for testing ecological and physiological roles of secondary compounds in living lichens. Symbiosis-Rehovot 30:301-316

Solhaug KA, Gauslaa Y (2012) Secondary lichen compounds as protection agatinst excess solar radiation and herbivores. Prog Bot 73:283-304

Solhaug KA, Lind M, Nybakken L, Gauslaa Y (2009) Possible functional roles of cortical depsides and medullary depsidones in the foliose lichen Hypogymnia physodes. Flora 204:40-48. https:// doi.org/10.1016/j.flora.2007.12.002

Swanson A, Fahselt D, Smith D (1996) Phenolic levels in Umbilicaria americana in relation to enzyme polymorphism, altitude and sampling date. Lichenologist 28:331-339. https://doi.org/10. 1006/lich.1996.0030

Vatne S, Asplund J, Gauslaa Y (2011) Contents of carbon based defence compounds in the old forest lichen Lobaria pulmonaria vary along environmental gradients. Fungal Ecol 4:350-355. https://doi.org/10.1016/j.funeco.2011.03.007

Venables WN, Ripley BD (2002) Modern applied statistics with S, 4th edn. Springer, New York

Walton DWH (1982) The Signy Island terrestrial reference sites: XV. Micro-climate monitoring, 1972-1974. Brit Antarct Surv Bull $55: 111-126$

Publisher's Note Springer Nature remains neutral with regard to jurisdictional claims in published maps and institutional affiliations. 